\title{
Soil hardness of burrows related to the usage frequencies of the lesser Japanese mole, Mogera imaizumii (Talpidae)
}

\author{
Masahiro A. Iwasa* \& Mao Takahashi
}

\begin{abstract}
The soil hardness inside burrows was studied in the lesser Japanese mole, Mogera imaizumii, to evaluate differences in the hardness of the ground surface, sidewalls, and bottoms of regular burrows (high usage frequency, $R \mathrm{~b}$ ) and temporary burrows (low usage frequency, $T \mathrm{~b}$ ). We analyzed usage frequency at 68 burrow points by setting snare-type tube traps, which triggered responses by the moles, at each burrow point to record the usage of moles without capturing them. These burrow points were classified as $R \mathrm{~b}$ or $\mathrm{Tb}$ based on the presence or absence of a response, respectively, sixteen hours after being set; 20 burrow points were identified as $R \mathrm{~b}$, and 48 were identified as $T \mathrm{~b}$. No differences in the frequencies of $R \mathrm{~b}$ and $T \mathrm{~b}$ were observed relation to the depth, which is related to the vertical gradient of hardness. In addition, newly detected burrows were more frequently found to be $T \mathrm{~b}$ than in $R \mathrm{~b}$ during early spring to summer, which seems to be related to mole dispersal. Moreover, we measured the soil hardness of the ground surface, sidewalls, and bottoms of the burrows at the 68 burrow points. On comparisons of the relationships between the soil hardness and the burrow usage frequency, we found that the bottoms were significantly harder in $R \mathrm{~b}$ than in $T \mathrm{~b}$. Therefore, the hardness of the bottom soil in $R \mathrm{~b}$ is considered to have been caused by the frequent treading of mole movements.
\end{abstract}

How to cite this article: Iwasa M.A., Takahashi M. 2021. Soil hardness of burrows related to the usage frequencies of the lesser Japanese mole, Mogera imaizumii (Talpidae) // Russian J. Theriol. Vol.20. No.2. P.129-135. doi: 10.15298/rusjtheriol.20.2.02

KEY WORDS: Mogera imaizumii, burrow, soil hardness, usage frequency.

Masahiro A. Iwasa [iwasa.masahiro@nihon-u.ac.jp], Mao Takahashi, College of Bioresource Sciences, Nihon University, Fujisawa, Kanagawa 252-0880, Japan.

\section{Связь твердости почвы нор и частоты их использования малым японским кротом, Mogera imaizumii (Talpidae)}

\begin{abstract}
М.А. Иваса*, М. Такахаши
РЕЗЮМЕ. Исследована твердость почвы внутри нор малого японского крота, Mogera imaizumii, оценены различия в твердости поверхности земли, боковых стенок и дна постоянных нор $(R b$, высокая частота использования нор) и временных нор ( $\mathrm{Tb}$, низкая частота использования нор). Для оценки частоты использования 68 нор были использованы специальные туннельные ловушки, которые отмечали движение кротов, без их отлова. Норы были классифицированы как $R \mathrm{~b}$ или $T \mathrm{~b}$ на основании наличия или отсутствия ответа, соответственно, через 16 часов после установки ловушек; 20 нор были идентифицированы как $R \mathrm{~b}$ и 48 были идентифицированы как $T \mathrm{~b}$. Никаких различий в частотах использования $R \mathrm{~b}$ и $T \mathrm{~b}$ в зависимости от глубины не наблюдалось, что связано с вертикальным градиентом твердости. Кроме того, в период с ранней весны до лета новые норы чаще идентифицировались как $T \mathrm{~b}$, чем $R \mathrm{~b}$, что, по-видимому, связано с расселением кротов. Мы измерили твердость почвы на поверхности земли, боковых стенках и дне в 68 норах. При сравнении соотношений между твердостью почвы и частотой использования нор мы обнаружили, что дно было значительно более твердым в $R \mathrm{~b}$, чем в $T \mathrm{~b}$. Предполагается, что твердость грунта на дне в норах $R \mathrm{~b}$ обусловлена частотой перемещения кротов.
\end{abstract}

КЛЮЧЕВЫЕ СЛОВА: Mogera imaizumii, нора, твердость почвы, частота использования.

* Corresponding author 


\section{Introduction}

Six species of moles (Soricomorpha, Talpinae) inhabit the Japanese Islands, excluding the peripheral small islands and Hokkaido (Abe, 1998, 1999; Ohdachi et al., 2015). These talpine moles have large forefeet with strong claws that are useful for digging in soil (Abe, 1991; Imaizumi, 1983; Yokohata, 1998). They usually construct burrow network structures underground and lead completely fossorial lifestyle (Yokohata, 1998; Yoshiyuki, 2002; Ohdachi et al., 2015). The burrow size, such as its diameter, reflects the body size of the mole as intra- and interspecific variations and is particularly useful for understanding geographic variations in the morphology that depend on the soil hardness (Makita, 1972; Abe, 1991; Hosoda \& Tsuyuguchi, 2000; Saito et al., 2003). For example, the body size of moles is generally larger in the plains than in the mountains and is closely related to the soil condition (Abe, 1974, 2001a, b). Thus, intra- and interspecific relationships have been studied based on the burrow size and the soil condition, particularly the soil hardness, and species competition in the ecology of the Japanese moles (Imaizumi \& Imaizumi, 1970; Nezu, 1990; Moribe \& Yokohata, 2011).

In contrast to the Japanese Islands, there are many species of fossorial burrowing small mammals, such as soricomorphs and rodents, in Eurasia and Africa (Lacey et al., 2000). The ecologically of these has been well studied, primarily that of moles and mole-rats, particularly the latter which is absent in the Japanese Islands (Ohdachi et al., 2015). These studies have shown, for example, that in areas with poor feeding resources, burrows are expanded in the total length, which consumes a high energetical cost in mole-rats and tuco-tuco (Davies \& Jarvis, 1986; Heth, 1989; Antinuchi \& Busch, 1992). In addition, in the relationship between the environment and behavior, it has been observed that some mole-rats burrow to deeper soils to escape from hot thermal stress (Šumbera et al., 2012) and Talpa europaea also burrow deeper to obtain earthworms under dry conditions (Saey et al., 2014). Moreover, considering the relationships among feeding resources, environment, soil condition, reproduction, and burrow architecture, the characteristics of burrow systems have also been evaluated in burrowing mammals (Fumilayo, 1977; Šumbera et al., 2003, 2007; Lövy et al., 2013, 2015). Furthermore, the European mole digs burrows within the top layers at newly cultivated farms to capture invertebrates and utilizes different burrows during different seasons (Mellanby, 1971). As a sexual difference, it is known that female and male moles construct different burrow systems and males tend to dig a long straight burrow, in contrast to the irregular burrow networks built by females (Mellanby, 1971). Moreover, Carotenuto et al. (2020) researched the geomechanical features of burrows among fossorial mammals and found that T. europaea prefers residential soils with a harder uniaxial compressive strength and higher density. Thus, burrow systems related to evolutionary ecological aspects have been well studied in moles and mole-rats.
As mentioned above (Abe, 1968; Makita, 1972; Yokohata, 1998), the Japanese talpine mole also constructs burrow networks and it has been suggested that these burrows can be classified into two types: permanent burrows and hunting burrows (Imaizumi, 1970; Makita, 1975; Yokohata, 1998). The former is considered to be arterial burrows with higher usage frequencies and the latter temporary burrows with lower usage frequencies. For example, one permanent burrow was used by mole individuals for 167 and 134 consecutive days over two years (Makita, 1975). In addition, temporary burrows have also been confirmed within the surface soil layers in the European mole, to enable the finding of food resources particularly in summer (Mellanby, 1971). Thus, usage frequencies are informative for understanding the relationship between burrow network structures and behavioral tendencies, such as searching for feeding resources, in moles. Generally, talpine moles move forward by strongly pushing and scratching the sidewalls of a burrow with the rotational motion of both forefeet (Tezuka, 1963; Yokohata, 1998; Kley \& Kearney, 2007). However, burrow floors are merely trodden down by their small hindfeet due to body weight. Therefore, it is expected that the soils of sidewalls would be harder in permanent burrows than in temporary burrows based on the burrow usage frequency. However, such structures and characteristics of burrows have never been researched on the basis of their usage frequency in fossorial burrowing moles and mole-rats. In this study, we analyzed the soil hardness of burrows of in a population of the lesser Japanese mole, Mogera imaizumii (Kuroda, 1957), to evaluate the relationship between the physical characteristics of the burrows and the usage frequency.

\section{Materials and methods}

Our research was performed on a farm of Nihon University in Fujisawa, Kanagawa Prefecture, Japan $\left(35.37^{\circ} \mathrm{N}, 139.45^{\circ} \mathrm{E}, 28 \mathrm{ha}\right)$ from June 2013 through December 2014 (Fig. 1), where only M. imaizumii occurs as a fossorial mammal (Ohdachi et al., 2015). In this research area, 54 individuals of $M$. imaizumii were collected from 2006 to 2009 (Kuroi \& Iwasa, 2016). Therefore, it is estimated that there are a substantial number of individuals in the current research area. The research area mainly consists of grasses and Japanese cedar forests with scarce grasses on the floor, and the deep underground also consists of a loam layer of volcanic ash accumulated from Mt. Fuji and Mt. Hakone during the late Quaternary (Naruse, 1963; Oka et al., 1979).

During the research period, burrow points were searched for by piercing a metal peg (diameter $7 \mathrm{~mm}$ ) into the soil of the research area on each research day. In total, 68 burrow points were newly and randomly discovered each research day and were researched for the usage frequency of burrows by moles. To confirm the usage frequencies of the burrows, snare-type tube traps (inner diameter $40 \mathrm{~mm}$, Daishin Kogyo, Co., Ltd.) that we 


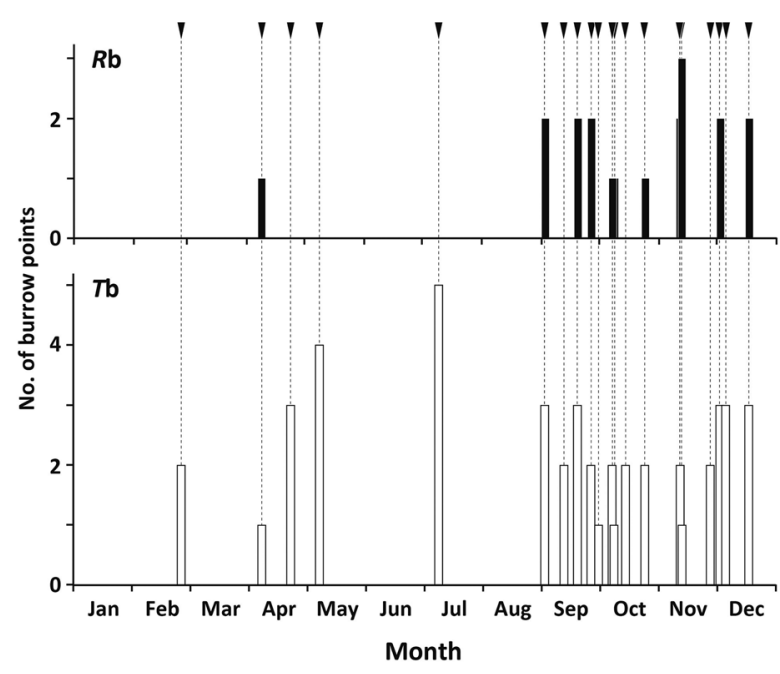

Fig. 1. Numbers of burrow points recognized as regular burrows $(R \mathrm{~b})$ and temporary burrows $(\mathrm{Tb})$ on each research date (arrowheads).

have been used in our previous studies to capture moles were set at the burrow points. In the current research, it was expected that the removal of mole individuals by capturing would influence the frequency of burrow usage. Therefore, to avoid capturing moles, we deliberately set traps with a trigger off only to induce the mole's attention and to lead moles to any response (mainly filling soil inside a trap or a trap movement by digging around a trap) when a mole would come to each burrow point. Considering the daily cycles of rest and activity phases in moles, Mogera and Talpa (Makita, 1975; Woods \& Mead-Briggs, 1978; Imaizumi, 1983; Yokohata, 1998; Di Febbraro \& Loy, 2014), we checked the traps for responses after sixteen hours (after two cycles at least) by setting the traps, and the burrows were then divided into two types based on the results. Burrow points with any responses by moles were classified as regular burrows (high usage frequency as a permanent gallery, hereafter referred to as $R \mathrm{~b}$ ), and those with no response were classified as temporary burrows (low usage frequency as a hunting gallery, hereafter referred to as $T \mathrm{~b}$ ).

To measure the height and width of the burrows and the soil hardness of the ground surface (GS), side (S), and bottom (B) of each burrow point, we used a caliper to determine the height and the width $(\mathrm{mm})$ of the burrows and a push-cone pressure meter (DIK-5553, Daiki Rika Kogyo, Co., Ltd., Fig. 2) to determine the hardness $\left(\mathrm{kg} / \mathrm{cm}^{2}\right)$. The depth from the ground surface to the bottom of the burrow was also measured because it is closely related to the gradient of vertical soil hardness in mole burrowing (Abe, 2001b; Fig. 2). All measurement values (mean $\pm S D$ ) were compared using the TukeyKramer HSD test as a multiple comparison in ANOVA. In addition, the differences between GS and S (GS-S), between GS and B (GS-B), and between S and B (S-B) were also calculated to evaluate the relationships among them and between $R \mathrm{~b}$ and $T \mathrm{~b}$.

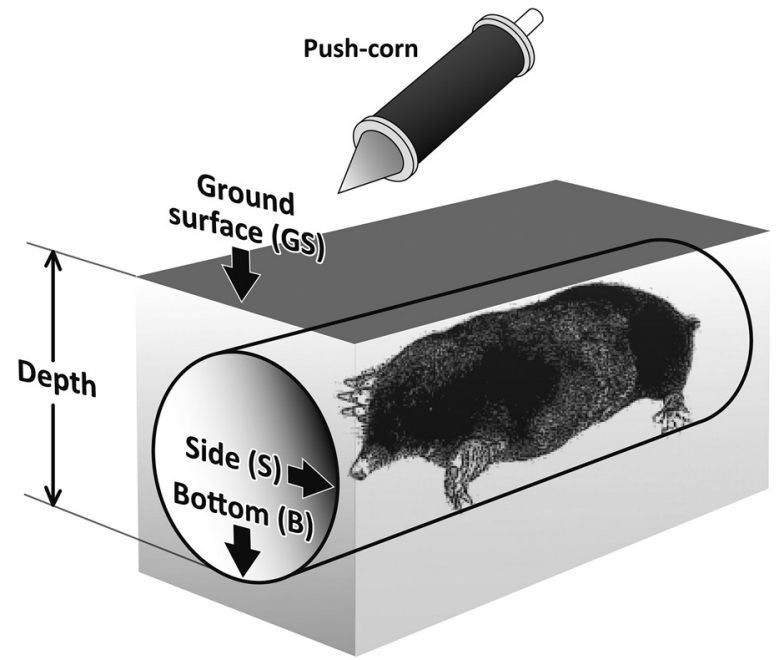

Fig. 2. Measurements of the soil hardness of the ground surface (GS), side (S) and bottom (B) at each burrow point.

\section{Results}

On the basis of the responses to the mole traps, 68 burrow points were classified as $20 \mathrm{Rb}$ and $48 \mathrm{~Tb}$. The burrow height and width did not significantly differ between $R \mathrm{~b}$ and $T \mathrm{~b}, 28.5 \pm 5.2 \mathrm{~mm}$ in $R \mathrm{~b}$ and $31.2 \pm$ $8.2 \mathrm{~mm}$ in $\mathrm{Tb}(p=0.1260)$ in the former and $35.5 \pm$ $8.1 \mathrm{~mm}$ in $R \mathrm{~b}$ and $35.3 \pm 8.3 \mathrm{~mm}$ in $\mathrm{Tb}(p=0.9430)$ in the latter. A significant difference in the depths of burrows between $R \mathrm{~b}(125.0 \pm 24.4 \mathrm{~mm})$ and $T \mathrm{~b}(133.9 \pm$ $40.2 \mathrm{~mm}$ ) was not obtained ( $p=0.2748$, Fig. 3A). On the other hand, $R \mathrm{~b}$ were mainly discovered from September to December, and detections of $T \mathrm{~b}$ were more frequent than those of $R \mathrm{~b}$ (Fig. 1). Particularly, most discoveries from February to July were $T \mathrm{~b}$, with the exception of one example of $R \mathrm{~b}$ (Fig. 1).

The soil hardness of GS, S and B was determined to be $2.17 \pm 1.85 \mathrm{~kg} / \mathrm{cm}^{2}, 1.64 \pm 0.75 \mathrm{~kg} / \mathrm{cm}^{2}$, and $2.31 \pm$ $1.55 \mathrm{~kg} / \mathrm{cm}^{2}$, respectively, in $R \mathrm{~b}$ and $1.67 \pm 1.81 \mathrm{~kg} / \mathrm{cm}^{2}$, $1.30 \pm 0.83 \mathrm{~kg} / \mathrm{cm}^{2}$, and $1.51 \pm 0.89 \mathrm{~kg} / \mathrm{cm}^{2}$, respectively, in $T \mathrm{~b}$, and these values were statistically compared (Fig. $3 \mathrm{~B})$. The measurements were not significantly different between $R \mathrm{~b}$ and $\mathrm{Tb}$ for $\mathrm{GS}(p=0.4053)$ and $\mathrm{S}(p=$ $0.7884)$. In addition, significant hardness differences between $\mathrm{S}$ and $\mathrm{B}$ were not confirmed in $R \mathrm{~b}(p=0.4482)$ and in $\mathrm{Tb}(p=0.9922)$ (Fig. 3B). Only those of B differed significantly ( $p=0.0336$ ) between $R \mathrm{~b}$ and $T \mathrm{~b}$. Accordingly, these data indicate that the frequent usage of burrows causes stronger treading and hardness of soil in B than in S. Moreover, in GS-S, GS-B, and S-B at each burrow point, only the S-B indices were significantly smaller in $R \mathrm{~b}$ than in $T \mathrm{~b}$ with significance $(p=0.0253)$ and most of the $\mathrm{S}-\mathrm{B}$ range in $R \mathrm{~b}$ was $<0$ (Fig. $3 \mathrm{C}$ ). This result indicated that the soil of $\mathrm{B}$ is constantly harder than that of $\mathrm{S}$ in $R \mathrm{~b}$. Such a tendency is in accordance with the significant difference in the hardness of $\mathrm{B}$ between $R \mathrm{~b}$ and $T \mathrm{~b}$, caused by the usage frequency (Fig. 3C). 


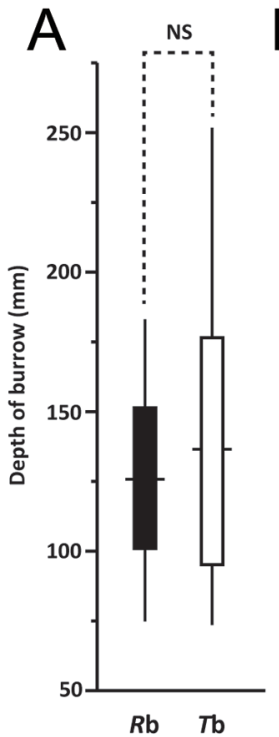

B

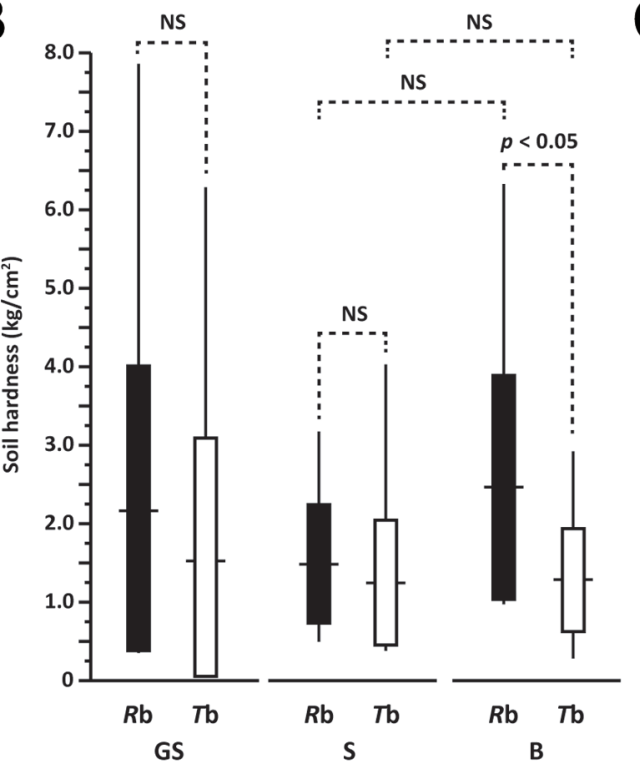

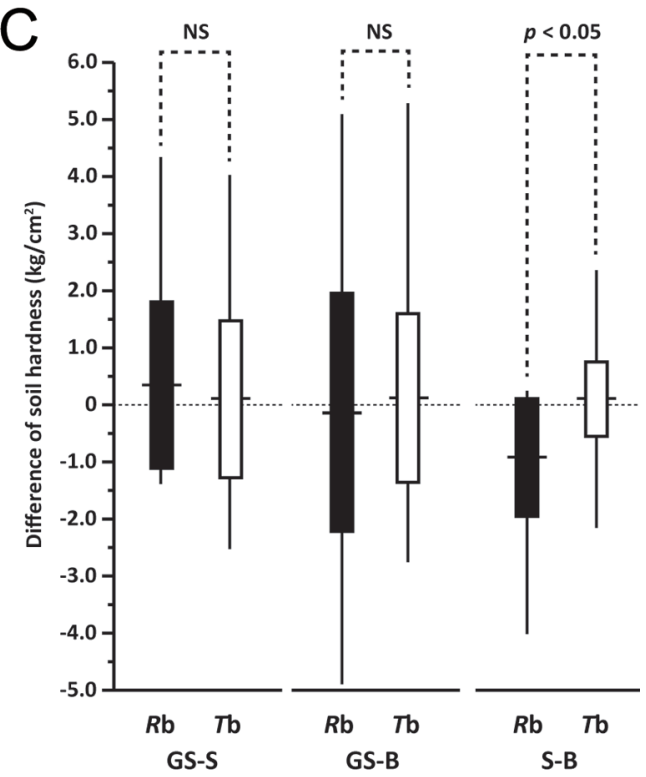

Fig. 3. Comparisons of the burrow depth between $R \mathrm{~b}$ and $T \mathrm{~b}(\mathrm{~A})$, the hardness of $\mathrm{GS}, \mathrm{S}$, and $\mathrm{B}$ soils of burrows for Rb and $\mathrm{Tb}$ (B) and a comparison of the differences among the hardness of GS, S, and B soils (C). Vertical and horizontal bars indicate ranges and averages with $S D$ by rectangles, respectively. Statistical differences by multiple comparisons are identified as not significant (NS) or significant with $\mathrm{p}$ values for combinations indicated by dotted lines.
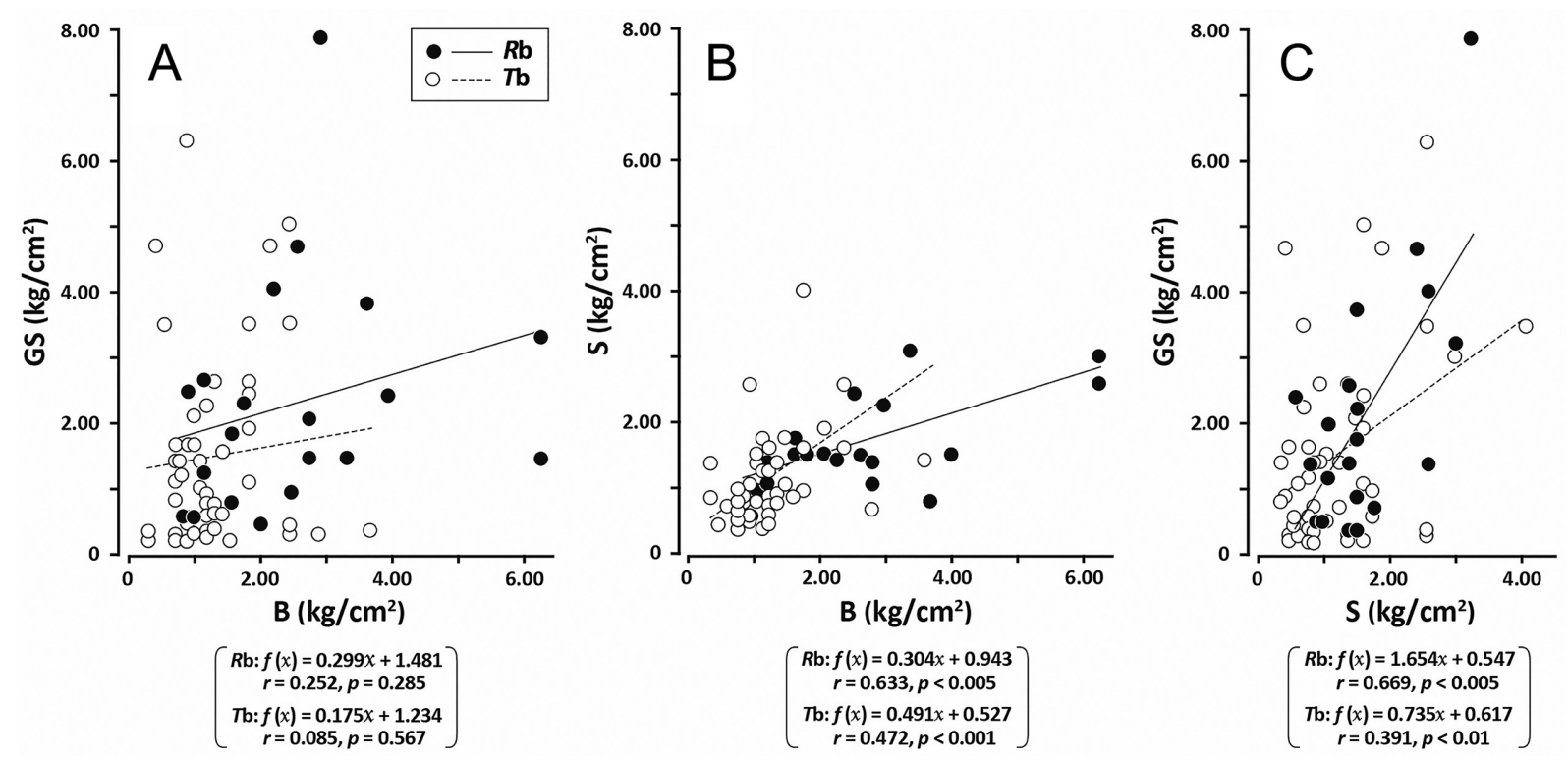

Fig. 4. Scatterplots for relationships of the hardness of GS, S, and B soils for $R \mathrm{~b}$ and $T \mathrm{~b}$. The correlation $(r)$, its significance $(p)$, and the regression formula $\mathrm{f}(x)$ are indicated at bottom of each graph.

Moreover, the relationships among the hardness of GS, S, and B were represented as scatterplots with each regression line and its formula (Fig. 4). In these relationships, the hardness of the GS and B soils was not correlated in both burrow types (Fig. 4A). However, the hardness of the GS and S soils was significantly correlated in both burrow types (Fig. 4C). Thus, the hardness of the GS soil reflects that of S, to some extent. In addition, it is estimated that $R \mathrm{~b}$ have been constructed on harder ground surfaces, considering the inclinations of the $f(x)$ formulae (1.654 in $R \mathrm{~b}>0.735$ in Tb in Fig. 4C). On the other hand, the relationship of S and B indicated that the soil of $\mathrm{B}$ in both burrow types was harder than that of S (Fig. 3B, Fig. 4B). In addition, the inclinations of their formulae $(0.304$ in $R \mathrm{~b}<0.491$ in $T \mathrm{~b}$ in Fig. 4B) estimated that the soil of $\mathrm{B}$ of $R \mathrm{~b}$ would be harder than that of $T b$ (Fig. 4). This is in close accordance with the comparison of $R \mathrm{~b}$ and $T \mathrm{~b}$ (B in Fig. $3 \mathrm{~B}, \mathrm{~S}-\mathrm{B}$ in Fig. $3 \mathrm{C}$ ). 


\section{Discussion}

As in the annual detections of burrow types in this study (Fig. 1), from February to July, Tb was mainly discovered despite $R \mathrm{~b}$ being infrequently detected. According to a previous study (Kuroi \& Iwasa, 2016) on the annual changes in the male genital condition morphometrically and histologically, it is estimated that the breeding of $M$. imaizumii occurs from late winter through spring in the current research area. Therefore, the period from February to July seems to correspond to the dispersal season of its young individuals (Yokohata, 1998). Namely, the frequent detection of $T b$ during early spring to summer would mean that young moles under dispersal would construct new burrows from winter to spring. On the other hand, a lower number of detections of $R \mathrm{~b}$ would mean the frequent use of certain burrows that had already been dug, likely by multiple moles. These results for $R \mathrm{~b}$ and $T \mathrm{~b}$ are in close accordance with the findings of Tezuka (1963). However, we researched the usage frequency with only one-time confirmation of mole responses at each burrow point newly detected throughout a year and it is impossible to refer to seasonal differences in repetitive usage frequencies because of the scarce data.

Previous findings (Tezuka, 1963; Yokohata, 1998; Kley \& Kearney, 2007) have indicated that talpine moles generally move forward by strongly scratching the sidewalls of a burrow with the rotational motion of both robust forefeet bearing sharp, stout claws. Thus, we primarily expected that the soils of S would be harder in $R \mathrm{~b}$ than in $\mathrm{Tb}$ considering the specific motion of moles. However, the current results revealed that the soil of $\mathrm{B}$ was harder than that of $\mathrm{S}$ in $R \mathrm{~b}$ irrespective of the ground surface condition and depth condition (Figs. 3 and 4) and our expectation was not consistent with our research results. This fact suggests that moles tread down the bottom of burrows by frequently passing through the burrows in $R \mathrm{~b}$ more than in $\mathrm{Tb}$ and do not strongly push the sidewalls with their robust forefeet in their forward moving motion. On the basis of the present results, it is concluded that the difference in the usage frequency of burrows is reflected in the soil hardness of B and our classification of $R \mathrm{~b}$ and $T \mathrm{~b}$ tended to be pertinent in spite of the one-time detections.

To date, some studies have considered the soil condition to be related to ecological factors in European talpine moles. For example, Funmilayo (1977) indicated that the soil type does not significantly influence the density and distribution of T. europaea, whereas food resources are the main contributors. In contrast, it has been revealed that $T$. occidentalis prefers soft soil conditions as its habitat, in the same manner as it prefers a higher coverage of grass and a lower coverage of rocks (López de Hierro et al., 2013). In addition, T. europaea also tends to avoid stony soil to effectively construct a burrow system (Milner \& Ball, 2009). Moreover, such habitat preferences related to the soil conditions are recognized in $T$. romana (Loy et al., 1994). Carotenuto et al. (2020) also suggested that the residential soils preferred by $T$. europaea show a harder uniaxial compressive strength and higher density based on the geomechanical findings. This means that talpine moles tend to prefer relatively stronger soils than other fossorial mammals, to secure burrows fitting their bodies. However, burrow characteristics as related to the usage frequency as in our findings have never been studied in a population of a mole species.

Previous studies, particularly on the Japanese talpines, have mainly focused on the relationships between the soil condition and intraspecific geographic variations in the morphology, particularly the body sizes (Abe, 1974, 1996) and between the soil condition and the distribution patterns of the Japanese talpine mole from the standpoint of interspecific competition, such as between $M$. imaizumii and $M$. wogura (Abe, 1974, 1999, 2001a, b, 2010; Nezu, 1990; Hosoda \& Tsuyuguchi, 2000; Saito et al., 2003; Moribe \& Yokohata, 2011) and between M. imaizumii and M. etigo (formerly M. tokudae) (Imaizumi \& Imaizumi, 1970; Hashimoto \& Abe, 2001). Unlike European moles, the burrow physical features in a population have never been researched in Japanese moles. Thus, it is necessary to reconfirm whether the present tendencies of the characteristics of inside burrows depending on the usage frequency would also be recognized in other populations of $M$. imaizumii and/or other mole species. In addition, further physical characterization of burrows with a more refined viewpoint as in Carotenuto et al. (2020) would contribute to a clearer discrimination of $R \mathrm{~b}$ and $T \mathrm{~b}$. To conclude, we could clarify physical differences between $R \mathrm{~b}$ and $T \mathrm{~b}$ in this study and it seems that our subject can be useful to evaluate the relationship between behavioral tendencies and burrow characteristics in other burrowing species from an ecological standpoint.

\section{References}

Abe H. 1968. Classification and biology of Japanese Insectivora (Mammalia). I. Biological aspects // Journal of Faculty of Agriculture, Hokkaido University. Vol.55. P.429-458.

Abe H. 1974. [Change of the boundary-line of two moles distributions in a period of 14 years] // Journal of Mammalogical Society of Japan. Vol.6. P.13-23 [in Japanese with English summary].

Abe H. 1991. [Trapping methods of insectivores] // Mammalian Science. Vol.31. P.139-143 [in Japanese].

Abe H. 1996. Habitat factors affecting geographic size variation in Japanese moles // Mammal Study. Vol.21. P.71-87.

Abe H. 1998. [Taxonomy and morphology of Talpidae] // Abe H. \& Yokohata Y. (eds.). [The Natural History of Insectivora (Mammalia) in Japan]. Shobara: Hiba Society of Natural History. P.25-58 [in Japanese].

Abe H. 1999. Nation-wide investigation of moles in Japan geographic and interspecific variations of an insectivore // Yokohata Y. \& Nakamura S. (eds.). Recent Advances in the Biology of Japanese Insectivora. Proceedings of the Symposium on the Biology of Insectivores in Japan and on the Wildlife Conservation. Shobara: Hiba Society of Natural History. P.15-19. 
Abe H. 2001a. [Isolated relic populations and their keeping mechanisms in moles] // Mammalian Science. Vol.41. P.35-52 [in Japanese with English summary].

Abe H. 2001b. Soil hardness, a factor affecting the range expansion of Mogera wogura in Japan // Mammal Study. Vol.26. P.45-52.

Abe H. 2010. [The northeastern front in the distribution of Mogera wogura in the central Honshu, Japan in 2009, especially the past 50 years' change in Nagano Prefecture] // Mammalian Science. Vol.50. P.55-66 [in Japanese with English summary].

Antinuchi C. \& Busch C. 1992. Burrow structure in the subterranean rodent Ctenomys talarum // Zeitschrift für Säugetierkunde. Vol.57. P.63-168.

Carotenuto A.R., Guarracino F., Šumbera R. \& Fralfi M. 2020. Burrowing below ground: interaction between soil mechanics and evolution of subterranean mammals // Journal of the Royal Society Interface. Vol.17. P.20190521.

Davies K.C. \& Jarvis J.U.M. 1986. The burrow systems and burrowing dynamics of the mole-rats Bathyergus suillus and Cryptomys hottentotus in the fynbos of the south-western Cape, South Africa // Journal of Zoology. Vol.209. P.125-147.

Di Febbraro M. \& Loy A. 2014. A new method based on indirect evidence to infer activity pattern in moles. A test on the blind mole in Central Apennines // Folia Zoologica. Vol.63. P.116-121.

Funmilayo O. 1977. Distribution and abundance of moles (Talpa europea L.) in relation to physical and food supply // Oecologia. Vol.30. P.277-283.

Hashimoto T. \& Abe M. 2001. Body size and reproductive schedules in two parapatric moles, Mogera tokudae and Mogera imaizumii, in the Echigo Plain // Mammal Study. Vol.26. P.35-44.

Heth G. 1989. Burrow patterns of the mole rat Spalax ehrenbergi in two soil types (terra-rossa and rendzina) in Mount Carmel, Israel // Journal of Zoology. Vol.217. P.39-56.

Hosoda T. \& Tsuyuguchi M. 2000. [Distribution of Mogera wogura Temminck and M. imaizumii Kuroda (Insectivora, Talpidae) in Wakayama Prefecture, Japan] // Nanki Seibutu. Vol.42. P.15-20 [in Japanese]

Imaizumi Y. 1970. [The Handbook of Japanese Land Mammals. Vol.1]. Tokyo: Shin-shicho-sha. 350 p. [in Japanese].

Imaizumi Y. 1983. [Hunting of moles] // Hidaka T. (ed.). [Meanings of Animal Behavior]. Hadano: Tokai University Press. P.123-147 [in Japanese].

Imaizumi Y. \& Imaizumi T. 1970. [Interspecific relationship in two mole species in the plains of Niigata, Honshu: 1. Geographic distribution] // Journal of Mammalogical Society of Japan. Vol.5. P.15-18 [in Japanese with English summary].

Kley N.J. \& Kearney M. 2007. Adaptation for digging and burrowing // Hall B.K. (ed.). Fins into Limbs: Evolution, Development, and Transformation. Chicago: University of Chicago Press. P.284-309.

Kuroi Y. \& Iwasa M.A. 2016. Activity of male internal genitalia and breeding season in the lesser Japanese mole inferred from morphometric and histological analyses // Mammal Study. Vol.41. P.25-30.

Lacey E., Patton J. \& Cameron G. 2000. Life Underground: The Biology of Subterranean Rodents. Chicago: University of Chicago Press. 449 p.
Lövy M., Skliba J. \& Sumbera R. 2013. Spatial and temporal activity patterns of the free-living giant mole-rat (Fukomys mechowii), the largest social bathyergid // PLoS One. Vol.8. P.e55357.

Lövy M., Skliba J., Hrouzkova E., Dvorakova V., Nevo E. \& Sumbera R. 2015. Habitat and burrow system characteristics of the blind mole rat Spalax galili in an area of supposed sympatric speciation // PLoS One. Vol.10. P.e0133157.

Loy A., Beolchini F., Martullo S. \& Capanna E. 1994. Territorial behaviour of Talpa romana in an olivegrove habitat in central Italy // Italian Journal of Zoology. Vol.61. P.207-211.

López de Hierro L.G., Moleón M., Lupiáñez D.G., Virgós E. \& Jiménez R. 2013. Positive and negative unintended human-induced effects on Iberian mole abundance at the edge of its distribution area // Mammalian Biology. Vol.78. P.276-282.

Makita Y. 1972. [Notes on Mogera kobeae] // Journal of Mammalogical Society of Japan. Vol.5. P.169 [in Japanese].

Makita Y. 1975. [Notes on Mogera kobeae (2)] // Journal of Mammalogical Society of Japan. Vol.6. P.140-141 [in Japanese].

Mellanby K. 1971. The Mole. London: William Collins Sons $\&$ Co Ltd. 160 p.

Milner C.B. \& Ball D.F. 2009. Factors affecting the distribution of the mole (Talpa europaea) in Snowdonia (North Wales) // Journal of Zoology. Vol.162. P.61-69.

Moribe J. \& Yokohata Y. 2011. Mixed distribution of Mogera imaizumii and Mogera wogura in the Tedori Alluvial Fan in Ishikawa Prefecture, Japan // Mammal Study. Vol.36. P.135-139.

Naruse Y. 1963. [Quaternary volcanic ashes in the Kanto Region] // Quaternary Research. Vol.3. P.94-109 [in Japanese with English summary].

Nezu K. 1990. [Distribution of Mogera kobeae and M. wogura from the Shiodo-shima Is., Kagawa Prefecture, Japan] // Kagawa Seibutsu. Vol.17. P.33-38 [in Japanese].

Ohdachi S.D., Ishibashi Y., Iwasa M.A., Fukui D. \& Saitoh T. 2015. The Wild Mammals of Japan. 2nd ed. Kyoto: Shoukadoh. $506 \mathrm{p}$.

Oka S., Shimazu M., Unozawa A., Katsurajima S. \& Kakimi T. 1979. [Geology of the Fujisawa District (Scale 1:50,000)]. Tsukuba: Geological Survey of Japan [in Japanese].

Saey T., van Meirvenne M., de Pue J., van de Vijver E. \& Delefortrie S. 2014. Reconstructing mole tunnels using frequency-domain ground penetrating radar// Applied Soil Ecology. Vol.80. P.77-83.

Saito K., Chinzei S. \& Tsuchiya K. 2003. [The investigation on the geographical distribution boundary of Mogera wogura and M. imaizumii in Fuji and Hakone area] // Animate. Vol.4. P.39-42 [in Japanese].

Šumbera R., Burda H., Chitaukali W.N. \& Kubova J. 2003. Silvery mole-rats (Heliophobius argenteocinereus, Bathyergidae) change their burrow architecture seasonally // Naturwissenschaften. Vol.90. P.370-373.

Šumbera R., Mazoch V., Patzenhauerová H., Lövy M., Šklíba J., Bryja J. \& Burda H. 2012. Burrow architecture, family composition and habitat characteristics of the largest social African mole-rat: the giant mole-rat constructs really giant burrow systems // Acta Theriologica. Vol.57. P.121-130.

Šumbera R., Šklíba J., Elichová M., Chitaukali W.N. \& Burda H. 2007. Natural history and burrow system architecture 
of the silvery mole-rat from Brachystegia woodland // Journal of Zoology. Vol.77. P.77-84.

Tezuka H. 1963. [Note on the noticeable habit of Mogera wogura wogura (Temminck)] // Journal of Mammalogical Society of Japan. Vol.2. P.45-48 [in Japanese with English summary].

Woods J.A. \& Mead-Briggs A.R. 1978. The daily cycle of activity in the mole (Talpa europaea) and its seasonal changes, as revealed by radioactive monitoring of the nest // Journal of Zoology. Vol.184. P.563-572.
Yokohata Y. 1998. [The ecology of Talpidae] // Abe H. \& Yokohata Y. (eds.). [The Natural History of Insectivora (Mammalia) in Japan]. Shobara: Hiba Society of Natural History. P.67-187 [in Japanese].

Yoshiyuki M. 2002. [Notes on a tunnel of Mogera wogura wogura (Temminck, 1843) (Mammalia, Insectivora)] // Miscellaneous Reports of the National Park for Nature Study. Vol.34. P.157-162 [in Japanese with English summary]. 